\section{Distinct Biogeographic Phenomena Require a Specific Terminology: A Reply to Wilson and Sagoff}

In a recent publication (Essl et al. 2019), we proposed that the increasing number of range-expanding species that track human-induced environmental change warrant specific recognition in science and biodiversity management, and we proposed the term "neonative" for these taxa. In the present letter, we reply to two letters (Wilson 2020, Sagoff 2020) that criticized specific but different aspects presented in our publication. Although we disagree on several points with both authors, we agree that a broader discourse is needed for developing robust and widely accepted definitions and terms for the ever more important phenomenon of neonative species.

Our recent publication on rangeexpanding species tracking humaninduced environmental change (Essl et al. 2019) has led to questions regarding the validity of the concept we have put forward. Wilson (2019) raises several important issues about the usefulness of the term "neonative", which we proposed as a shorthand to describe range-expanding native species that track human-induced environmental change. In another letter, Sagoff (2020) argues that species' origin does not matter, because it is not associated with biologically or ecologically relevant differences.

We disagree with Wilson (2019) that the inherent difficulties and uncertainties in identifying neonatives invalidate the concept. If we consider a phenomenon distinct (and important), we should denote it by a distinct term. This is not only prerequisite to classifying real cases, however difficult this may be, but also clarifies thinking and fosters inclusion of such phenomena into the development of hypotheses and theory. In fact, making current uncertainties and knowledge gaps in delineating neonatives explicit will promote research on these topics and will ultimately lead to better science and also support more focused decision making. Giving up the development of standardized protocols (e.g., for assessing the impacts of alien species) in the face of large uncertainties has been suggested several times in invasion science (e.g., Ojaveer et al. 2015), but giving up studying such challenges would hinder the advancement of knowledge (Blackburn et al. 2014). The need to name such species is also evident in other studies, especially when dealing with the predicted massive range shifts or altered abundances caused by climate change (Carey et al. 2012, Scheffers and Pecl 2019) and the need to manage their impacts (Latombe et al. 2019). For example, for many people, native invaders are species that become abundant within their natural range after an anthropogenic disturbance (e.g., Simberloff et al. 2012), whereas neonatives expand to a range where they have not been present, at least not in the current interglacial. Having a clear terminology to distinguish both phenomena will promote efforts to 
monitor species redistribution from local to global scales, will help managers in developing strategies for dealing with these newly arriving species, and will permit to develop focused policies in the future.

Wilson (2019) also suggests that we should focus on impacts instead of biogeographical origin of species when prioritizing interventions. This argument echoes long-standing disputes in invasion science (e.g., Gilroy et al. 2017; but see Simberloff et al. 2011). However, there is clear evidence that species of different biogeographic origin-that is, alien, neonative, and native species-differ in many crucial characteristics (Engelkes et al. 2008, Essl et al. 2019) and that the rapidly increasing number of alien (Seebens et al. 2017) and neonative species (Scheffers and Pecl 2019) makes this distinction ever more important. Furthermore, waiting until impacts become apparent is unwise, because species management might then come too late to be efficient or even feasible (Pluess et al. 2012). We reemphasize here that our term, "neonative", does not come with any negative connotations; it therefore does not a priori call for active management actions to control these species or to stop their spread. Decisions on which species to manage will be context dependent and will require ecological, social, and economic considerations.

Wilson (2019) also questions the usefulness of defining specific thresholds for applying the concept of neonative species because, he argues, it is pointless to "[draw] a line through a continuous process." We agree (and explicitly state this in our publication) that the processes involved in rangeexpansions of native species tracking human-induced environmental change are continuous. However, this is also the case for many other phenomena in ecology and other disciplines, such as endemism (What is the maximum area of occurrence to qualify a species as endemic?), alien species (What is the level of human assistance to qualify a species as alien?), or the Anthropocene (At which point in time has the human impact on Earth systems become so pervasive that a new geological epoch should be denoted?). Therefore, the fact that underlying processes are continuous does not mean that it is not useful to define different categories along this continuum. Such definitions come with thresholds and are the basis for investigating separate phenomena on the continuum. Otherwise, these differences would be ignored.

Finally, Wilson (2019) states that the term "neonative" has been used previously in different contexts, and therefore argues that applying it may cause confusion. We explained that the term "neonative" has indeed been used in other contexts but that it has not gained widespread usage in other fields. There are many essential terms in ecology (e.g., invasive, endemic) that have other meanings in other fields (e.g., in these cases, medicine and epidemiology) and that were used well before they were taken up in invasion science; there is little evidence that this caused confusion among scholars.

Sagoff (2020) raises the question of whether the native-alien distinction, however refined, correlates with any biological or ecological difference. We believe that his interpretation is unhelpful in resolving the debate. Of course, the mode of relocation and subsequent range expansion (directly or indirectly assisted by humans or naturally-i.e., on their own means) may differ and this can also result in evolutionary change of the properties of individuals (postinvasion niche shift; see e.g., Colautti and Lau 2015). Furthermore, the nonrandomness of transport leads to propagules with certain characteristics being more likely picked up and relocated than others. Accordingly, species of different biogeographical origin and modes of introduction do differ in their characteristics from species that originated at a location. This has been clearly elucidated in many studies and for many taxa (Engelkes et al. 2008, Simberloff et al. 2013), although this might not be true in every case, such as in
Sagoff's example. In addition, ecological novelty-more specifically, the lack of ecoevolutionary experience of resident species (Saul and Jeschke 2015) - has been shown to cause increased impacts on resident biota (Ricciardi and Atkinson 2004, Richardson and Ricciardi 2013).

Given the high and increasing relevance of species tracking humaninduced environmental change, we are pleased that our publication has initiated this debate. The question of how to define, identify, and possibly manage neonatives where appropriate in our human-dominated world will be crucial. In our view, an explicit recognition of this phenomenon in science, conservation management, and policymaking is urgently needed. Our publication has laid the foundation for this discourse. Importantly, we believe that this debate should become a broad one, involving scholars from different disciplines and environmental managers and decision-makers, so that arguments from different perspectives will be put forward. We also believe that this process should finally lead to the development of widely accepted standards and definitions-ideally overseen by relevant international bodies such as the IUCN, CBD, and IPBES. We see this debate as a contribution to this goal.

FRANZ ESSL, STEFAN

DULLINGER, PIERO GENOVESI, PHILIP E. HULME, JONATHAN M. JESCHKE, STELIOS KATSANEVAKIS, INGOLF KÜHN, BERND LENZNER, ANÍBAL PAUCHARD, PETR PYŠEK, WOLFGANG RABITSCH, DAVID M. RICHARDSON, HANNO SEEBENS, MARK VAN KLEUNEN, WIM H. VAN DER PUTTEN, MONTSERRAT VILÀ, AND SVEN BACHER

FranzEssl (franz.essl@univie.ac.at), Stefan Dullinger, and Bernd Lenzner are affiliated with the Division of Conservation Biology, Vegetation, and Landscape Ecology, in the Department 
of Botany and Biodiversity Research, at the University of Vienna, in Vienna, Austria. Franz Essl and David M.

Richardson are affiliated with the

Centre for Invasion Biology, in the Department of Botany and Zoology at Stellenbosch University, in Stellenbosch,

South Africa. Piero Genovesi is affiliated with the Institute for Environmental

Protection and Research and is chair of the International Union for Conservation of Nature's Species Survival Commission Invasive Species Specialist Group, in Rome, Italy. Philip E. Hulme is affiliated with the Bio-Protection Research Centre,

at Lincoln University, in Christchurch,

New Zealand. Jonathan M. Jeschke is affiliated with the Leibniz-Institute of Freshwater Ecology and Inland Fisheries, with Freie Universität Berlin's Department of Biology, Chemistry, and

Pharmacy's Institute of Biology, and with the Berlin-Brandenburg Institute of Advanced Biodiversity Research, all in

Berlin, Germany. Stelios Katsanevakis is affiliated with the University of the Aegean's Department of Marine Sciences,

in Mytilene, Greece. Ingolf Kühn is affiliated with the Helmholtz Centre for Environmental Research-UFZ's Department of Community Ecology and with Martin Luther University Halle-Wittenberg's Geobotany and Botanical Garden, in Halle, Germany, and is also affiliated with the German

Centre for Integrative Biodiversity Research Halle-Jena-Leipzig, in Leipzig,

Germany. Aníbal Pauchard is affiliated with the Laboratorio de Invasiones Biológicas, part of the Facultad de Ciencias Forestales, at the University of Concepcion, in Concepción, Chile, and with the Institute of Ecology and

Biodiversity in Santiago, Chile. Petr

Pyšek is affiliated with the Czech Academy of Sciences' Institute of Botany,

Department of Invasion Ecology, in

Prühonice, in the Czech Republic, and with the Department of Ecology, in the Faculty of Science, at Charles University, in Prague, in the Czech Republic. Wolfgang Rabitsch is affiliated with Environment Agency Austria's Department of Biodiversity and Nature Conservation, in Vienna, Austria. Hanno Seebens is affiliated with the Senckenberg Biodiversity and Climate Research Centre, in Frankfurt am

Main, Germany. Mark van Kleunen is affiliated with the Ecology division of the Department of Biology at the University of Konstanz, in Konstanz, Germany, and with the Zhejiang Provincial Key

Laboratory of Plant Evolutionary

Ecology and Conservation, at Taizhou University, in Taizhou, China. Wim $H$. van der Putten is affiliated with the Department of Terrestrial Ecology, at the Netherlands Institute of Ecology and with the Laboratory of Nematology at the Wageningen University and Research Centre, in Wageningen, in the Netherlands. Montserrat Vilà is affiliated with the Estación Biologica de Doñana (EBD-CSIC) in Sevilla and the Department of Plant Biology and

Ecology at the University of Seville, Spain. Sven Bacher is affiliated with the Department of Biology at the University of Fribourg, in Fribourg, Switzerland.

\section{References cited}

Blackburn TM, et al. 2014. A unified classification of alien species based on the magnitude of their environmental impacts. PLOS Biology 12 (art. e1001850)

Carey MP, Sanderson BL, Barnas KA, Olden JD. 2012. Native invaders: Challenges for science, management, policy, and society. Frontiers in Ecology and the Environment 10: 373-381.

Colautti R, Lau JA 2015. Contemporary evolution during invasion: Evidence for differentiation, natural selection, and local adaptation. Molecular Ecology 24: 1999-2017.

Engelkes T, et al. 2008. Successful range-expanding plants experience less above-ground and below-ground enemy impact. Nature 456: 946-948.

Essl F, et al. 2019. A conceptual framework for range-expanding species that track human-induced environmental change. BioScience 69: 908-919.

Gilroy JJ, Avery JD, Lockwood JL. 2017. Seeking international agreement on what it means to be "native." Conservation Letters 10: 238-247.

Latombe G, et al. 2019. A four-component classification of uncertainties in biological invasions: implications for management. Ecosphere 10: e02669.

Ojaveer H, et al. 2015. Classification of non-indigenous species based on their impacts: considerations for application in marine management. PLOS Biology 13 (art. e1002130). https://doi.org/10.1371/ journal.pbio.1002130.

Pluess T, Jarošík V, Pyšek P, Cannon R, Pergl P, Breukers A, Bacher S. 2012. Which factors affect the success or failure of eradication campaigns against alien species? PLOS ONE 7 (art. e48157). https://doi.org/10.1371/journal.pone.0048157.

Ricciardi A, Atkinson SK. 2004. Distinctiveness magnifies the impact of biological invaders in aquatic ecosystems. Ecology Letters 7: 781-784.

Richardson DM, Ricciardi A. 2013. Misleading criticism of invasion science: a field guide. Diversity and Distributions 19: 1461-1467.

Sagoff M. 2020. Comment on Essl and colleagues 2019. BioScience 70: 111-112.

Saul WC, Jeschke JM. 2015. Eco-evolutionary experience in novel species interactions. Ecology Letters 18: 236-245.

Scheffers BR, Pecl G. 2019. Persecuting, protecting or ignoring biodiversity under climate change. Nature Climate Change 9: 581-586.

Seebens H, et al. 2017. No saturation in the accumulation of alien species worldwide. Nature Communications 8 (art. 14435). doi:10.1038/ncomms14435.

Simberloff D, 141 Signatories. 2011. Nonnatives: 141 scientists object. Nature 475: 36 .

Simberloff D, Souza L, Nuñez MA, BarriosGarcia MN, Bunn W. 2012. The natives are restless, but not often and mostly when disturbed. Ecology 93: 598-607.

Simberloff D, et al. 2013. Impacts of biological invasions: What's what and the way forward. Trends in Ecology and Evolution 28: 58-66.

Wilson JRU. 2020. Definitions can confuse: Why the "neonative" neologism is bad for conservation. BioScience 70: 110-111. 